\title{
How not to write in defense of threatened tortoises
}

\author{
Yehudah L. Werner
}

Department of Evolution, Systematics and Ecology, The Hebrew University of Jerusalem, 91904 Jerusalem, Israel Email: yehudah_w@yahoo.com

Date of publication (online): 26 September 2009 Date of publication (print): 26 September 2009 ISSN 0974-7907 (online) | 0974-7893 (print)

Editor: Aaron Bauer

\section{Manuscript details:}

Ms \# 02251

Received 06 July 2009

Final received 22 August 2008

Finally accepted 31 August 2009

Citation: Werner, Y.L. (2009). How not to write in defense of threatened tortoises. Journal of Threatened Taxa 1(9): 471-473.

Copyright: () Yehudah L. Werner 2009. Creative Commons Attribution 3.0 Unported License. JoTT allows unrestricted use of this article in any medium for non-profit purposes, reproduction and distribution by providing adequate credit to the authors and the source of publication.

Author Details: YeHUdAH L. WeRner has participated in founding the Society for the Protection of Nature in Israel; taught, in various capacities, vertebrate zoology and herpetology at the $\mathrm{He}$ brew University of Jerusalem during 1953-1999, and edited the Israel Journal of Zoology during 1973-1989. As Professor Emeritus he continues to research.

Acknowledgements: I thank Dorothee Huchon, Gila Kachila, Tal Pupko and Herve Seligmann for enlightening inputs, although not all of it could be accommodated here.
Abstract: Prudent use of the limited conservation resources rests on solid taxonomy data. This is a critical review of a taxonomy paper aimed at conservation but in itself not fully reliable ("Genetic evidence for premature taxonomic inflation in Middle Eastern tortoises", Parham et al., 2006, Proc. Calif. Acad. Sci. 57: 955-964). Its authors consider that unjustified naming of species is detrimental to conservation. This reviewer considers the paper flawed in (a) selection and reportage of voucher specimens, partly erroneous or inaccurate; (b) methods; (c) scientific reasoning and conclusions; and (d) clarity of argumentation. Hence even if the results are supported by the more solid results of others, the paper in itself is considered not to be sufficiently reliable for systematics or conservation.

Keywords: Conservation, DNA, Middle East, morphology, systematics, taxonomy, Testudo floweri, Testudo graeca, Testudo werneri

Abbreviations: MVZ - Museum of Vertebrate Zoology, University of California at Berkeley.

\section{INTRODUCTION}

Scientists comprise architects and bricklayers but the bricklayers depend upon the solidity of available bricks. Conservation relies on biodiversity data, primarily identification of taxa and definition of distribution ranges (Meffe \& Carroll 1997; Samper 2004; Secretariat of the Convention on Biological Diversity 2008). Here I analyze a taxonomic brick that seems insufficiently solid for the conservation effort for which it was manufactured, tortoise conservation in the Mediterranean basin, a global biodiversity hotspot for reptiles (Baha El Din et al. 2008). Even if some conclusions are externally supported, and indeed some are by Fritz et al. (2007), the paper in itself seems problematic. From its scientific reasoning down to punctuation this paper seems spattered with inaccuracy, while in science, as in court, inaccuracy of a witness degrades the evidence. I can give here only some examples.

The Spur-thighed Tortoise, Testudo graeca Linnaeus, 1758, is widespread across the ecologically heterogeneous Mediterranean basin and shows geographical variation. Local populations have been morphologically recognized as species or subspecies, amounting to 17 nominal subspecies (Fritz \& Havaš 2007). The validity of some has been contested on molecular grounds (Fritz et al. 2007), rendering conservation priorities a matter of scientific philosophy. Conservation is necessary because many of these populations have been over-exploited, by amateurs (Pérez et al. 2004), the pet trade (Lambert 1979, 1981, 1984), and for food (Beshkov 1993).

\section{Observations and Comments}

The paper reviewed (Parham et al. 2006a) aimed "to provide a genetic test for the newly recognized morphology based taxonomy in Middle Eastern T. graeca using a rapidly evolving molecular marker and specimens with well-documented locality data." Using phylogenies the authors concluded a recommendation to avoid using some "new" taxon names, including Testudo floweri Bodenheimer, 1935, despite admitting that taxa dropped might be revalidated by additional research.

The methodology of calculating phylogenies suffers the weakness that results depend on outgroups commonly chosen by less objective considerations. Parham et al. (2006a) overcame this by deriving outgroups from earlier results (Parham et al. 2006b). But the outgroups for that project had been chosen by those non-objective considerations. Moreover, one outgroup, Testudo kleinmanni, was based on a seemingly dubious voucher (see below).

The introduction is confusing, defining "taxonomic inflation" as the promotion of many subspecies to species but accusing it of introducing unfamiliar names. How so, if most were familiar subspecies names?

The authors seem to care for conservation but the paper's contribution remains 
unclear unless one reads the cited literature. In the Introduction's second paragraph the group is assigned conservation concern but this is not linked with the paper's aim. The Abstract does say that "an accurate understanding of major evolutionary lineages in this taxon is important for guiding conservation strategies" but this is not supported in the text. The Conclusions suggest that reducing taxonomic changes and unjustified taxa benefits conservation through improving the credibility of taxonomy. But the paper contains no foundation for this conclusion and it remains enigmatic what the benefits for conservation should be if a monotypic Testudo graeca were recognized, ranging from North Africa to Central Asia.

I agree with Parham et al.'s (2006a) attitude, that congruence of molecular and morphological distinction would support the taxa distinguished. But I do not agree that incongruent molecular and morphological variation, or overall low sequence divergence, must necessarily discredit any morphologically-distinguishable taxa compared, as done by them. Parham et al. (2006a) used "rapidly-evolving" portions of the mitochondrial DNA. This evolution is independent of selective pressures. Rates of DNA and phenotype evolution are separate (Bromham et al. 2002; Davies \& Savolainen 2006). One cannot disregard a potential scenario that two populations, recently physically separated, diverge under different selective pressures, leading to visible speciation that has outraced the monotonously evolving mtDNA. Such speciation could be expressed in untested parts of the genome. Another scenario for mtDNA comparisons failing to distinguish species derives from hybridization (Smith et al. 2008).

These potential scenarios reflect a truism. The lack of evidence from one character-group (here, partial DNA evidence) cannot automatically overrule evidence from another charactergroup (here, morphology). It is not easy to derive "does not exist" from "not observed". Specifically, DNA notwithstanding (Parham et al. 2006a; Fritz et al. 2007), I find it hard to lump the tortoises of the Golan plateau and of the adjacent Galilee, Israel, the former being larger, darker and more corrugated than the latter (Sivan \& Werner 1992). Could these differences reflect environmental effects on embryogenesis (Fox 1948; Werner 1961; Deeming 2004; Qualls \& Shine 1998)? The data available for chelonians (Du \& Ji 2003; Deeming 2004) fail to explain these morphological differences.

Under Materials, one outgroup, Testudo kleinmanni, is based on a single specimen of unknown origin. Its number, "MVZ 230361" (also in Parham et al. 2006b), actually belongs to a salamander in the MVZ's catalogue. Although listed in the material, this species is missing from the appendix of Parham et al. (2006a) that provides specimen details.

The selection of ingroup material seems unfortunate, particularly regarding the question whether the name T.g. floweri is justified. Incidentally, as subspecies (Hoofien 1967; Werner 1988) it is not involved in taxonomic inflation. The map (fig. 1) lacks geographical degrees and scale bar but the distance between the sampled type localities of $T$. floweri in the south and T. antakyensis and T. terrestris in the north approximates $600 \mathrm{~km}$. Although in this area such a South-North gap implies a dramatic ecological jump (Yom-Tov \& Tchernov 1988), this interval was not sampled. Had T. floweri differed from these northern samples, it would have been tantalizing not to know the affiliation of the intervening populations.
The quantitative sampling of localities, usually $\mathrm{N}=1$ per site, is surprising. If a character varies between two related taxa, it is likely to have varied within the common ancestral population. Indeed, characters that are stable and distinguish between some species, may vary within another species. Working with morphological characters, nobody would compare species without heeding intraspecific variation. In this respect it would have been sounder to adopt the strategies of Attum et al. (2007), Fritz et al. (2007) and Široký \& Fritz (2007) in DNA-verification of Testudo taxonomy.

The restriction of the sample of the questioned T. floweri to $\mathrm{N}=1$ is particularly problematic. Its collection locality in the MVZ web-posted catalogue, "near Newe Deqalim, Southern Gaza Strip" is inaccurate. The locality was "Probably near Newe Deqalim, etc.". The specimen, and another likewise deposited in MVZ but not utilized, were among tens collected by children and maintained by Mr. Eli Moses, Newe Deqalim, the "proxy collector". Mr. Moses, with the mediation of Dr. Ran Lapid, gave the specimens to me for sending to Parham and coauthor Papenfuss. I transmitted Mr. Moses's explanation that generally the tortoises originated from the vicinity but some may have been brought from elsewhere. Papenfuss considered this good enough. It would have been, had the results shown a difference. But for a negative result, the second, wasted, individual should have been sequenced. The probability that both were extralimital could be considered negligible.

Entering Parham, who only received the turtles from me, into the MVZ catalogue as collector, ignores the collector's roles as witness for the collection data and as source for details.

Moreover, the work with T. floweri has a worse flaw. Parham et al. (2006a) considered the type locality to be the Gaza Strip. But Bodenheimer (1935) had described the taxon from the "Negev" and his book contains a map that specifically excludes the Gaza strip from the Negev.

The Methods (Parham et al. 2006 a,b) ignore a point that most journals now require: how were the animals treated, and how were they killed? Space precludes reporting on faults at the copy-editing level.

\section{Conclusion}

In summary the paper is at all levels not sufficiently accurate to be considered a reliable brick that could in itself contribute to turtle taxonomy and conservation.

\section{References}

Attum, O., S. Baha El Din, S. Carranza, R. Earley, E.N. Arnold \& B. Kingsbury (2007). An evaluation of the taxonomic validity of Testudo werneri. Amphibia-Reptilia 28: 393-401.

Beshkov, V1. (1993). On the distribution, relative abundance and protection of tortoises in Bulgaria. Chelonian Conservation and Biology $1(1): 53-62$.

Bodenheimer, F.S. (1935). Animal Life in Palestine., L. Mayer, Jerusalem. Bromham, L., M. Woolfit, M.S.Y. Lee \& A. Rambaut (2002). Testing the relationship between morphological and molecular rates of change along phylogenies. Evolution 56: 1921-1930.

Davies, T.J. \& Y. Savolainen (2006). Neutral theory, phylogenies, and the relationship between phenotypic change and evolutionary rates. Evolution 60: 476-483.

Deeming, D.C. (2004). Post-hatching phenotypic effects of incubation in reptiles, pp. 229-251. In: Deeming, D.C. (ed.). Reptilian Incubation: Environment, Evolution and Behaviour. Nottingham University Press, Nottingham

Du, W.-G. \& X. Ji (2003). The effects of incubation thermal 
environments on size, locomotor performance and early growth of hatchling soft-shelled turtles, Pelodiscus sinensis. Journal of Thermal Biology 28: 279-286.

Fox, W. (1948). Effect of temperature on development if scutellation in the garter snake, Thamnophis elegans atratus. Copeia 1948: 252-262.

Fritz, U. \& P. Havaš (2007). Checklist of chelonians of the world. Vertebrate Zoology 57: 149-368.

Fritz, U., A.K. Hundsdörfer, P. Široký, M. Auer, H. Kami, J. Lehmann, L.F. Mazanaeva, O. Türkozan \& M. Wink (2007). Phenotypic plasticity leads to incongruence between morphology-based taxonomy and genetic differentiation in western Palaearctic tortoises (Testudo graeca complex; Testudines, Testudinidae). Amphibia-Reptilia 28: 97-121.

Hoofien, J.H. (1967). An alphabetical list of the reptiles of Israel according to the status on May $31^{\text {st }}$, 1967. Department of Zoology, Tel-Aviv University, Tel Aviv.

Lambert, M.R.K. (1979). Trade and the Mediterranean tortoises. Oryx 15: $81-82$.

Lambert, M.R.K. (1981). Temperature, activity and field sighting in the Mediterranean spur-thighed or common garden tortoise Testudo graeca. Biological Conservation 21: 39-54.

Lambert, M.R.K. (1984). Threats to Mediterranean (West Palaearctic) tortoises and their effects on wild populations: an overview. AmphibiaReptilia 5: 5-15.

Meffe, G.K. \& C.R. Carroll (eds.) (1997). Principles of conservation biology. Sinauer, Sunderland, Massachusetts

Parham, J.F., O. Türkozan, B.L. Stuart, M. Arakelyan, S. Shafei, J.R. Macey, Y.L. Werner \& T.J. Papenfuss (2006a). Genetic evidence for premature taxonomic inflation in Middle Eastern tortoises. Proceedings of the California Academy of Science 57: 955-964.

Parham, J.F., J.R. Macey, T.J. Papenfuss, C.R. Feldman, O. Türkozan, R. Polymeni \& J.L. Boore (2006b). The phylogeny of Mediterranean tortoises and their close relatives based on complete mitochondrial genome sequences from museum specimens. Molecular Phylogenetics and Evolution 38: 50-64.

Pérez, I, A. Giménez, J.A. Sánchez-Zapata, J.D. Anadón, M. Martínez \& M.A. Esteve (2004). Non-commercial collection of spur-thighed tortoises (Testudo graeca graeca): a cultural problem in southeast Spain. Biological Conservation 118: 175-181

Qualls, F.J. \& R. Shine (1998). Geographic variation in lizard phenotypes: importance of the incubation environment. Biological Journal of the Linnaean Society 64: 477-491.

Samper, C. (2004). Taxonomy and environmental policy. Philosophical Transactions of the Royal Society of London B 359: 721-728.

Secretariat of the Convention on Biological Diversity (2008). Guide to the global taxonomy initiative. Technical Series no. 30, Montreal, Canada.

Široký, P. \& U. Fritz (2007). Is Testudo werneri a distinct species? Biologia, Bratislava 62: 228-231.

Sivan, N. \& Y.L. Werner (1992). Survey of the reptiles of the Golan Plateau and Mt. Hermon, Israel. Israel Journal of Zoology 37: 193211.

Smith, M.A., N.A. Poyarkov, Jr. \& P.N.D. Hebert (2008). CO1 DNA barcoding amphibians: take the chance, meet the challenge. Molecular Ecology Resources 8: 235-246.

Werner, Y.L. (1988). Herpetofaunal survey of Israel (1950-85), with comments on Sinai and Jordan and on zoogeographical heterogeneity, pp. 355-388. In: Yom-Tov, Y. \& E. Tchernov (eds.). Zoogeography of Israel. Monographiae Biologicae 62, W. Junk, Dordrecht.

Yom-Tov, Y. \& E. Tchernov (eds.) (1988). Zoogeography of Israel, Monographiae Biologicae 62 W. Junk, Dordrecht.

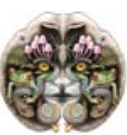

